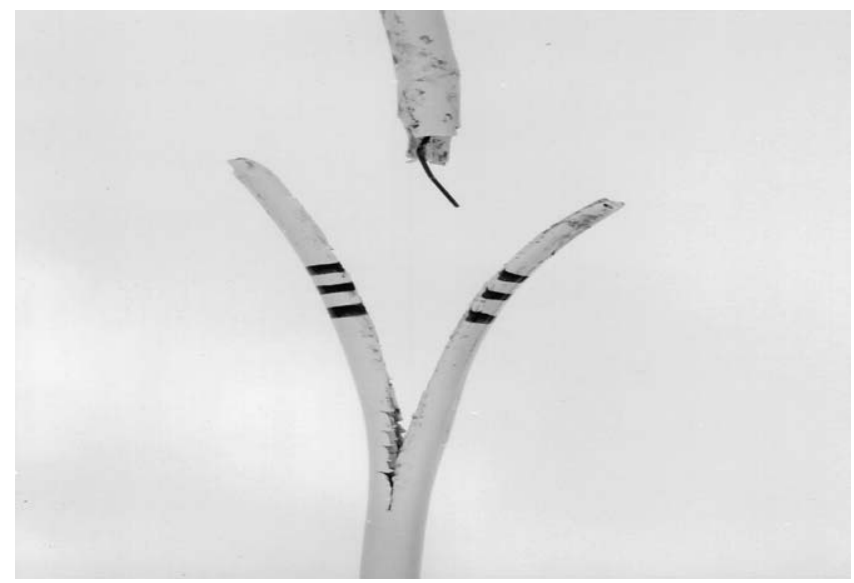

Fig. 1. The pulmonary artery catheter (with split end removed by traction) is shown, exactly split in the middle, with the other part (see the surgical suture rest) retrieved uneventfully by the cardiologist via the femoral vein.

\title{
Intracardiac entrapment of a pulmonary artery catheter
}

doi: 10.1111/j.1399-6576.2007.01321.x

Sir,

We report a case of intracardial pulmonary artery catheter (PAC) anchoring by a surgical suture and subsequent transfemoral Dotter retrieval snaring a $30-\mathrm{cm}$ fragment of a broken PAC during an attempt of forceful removal. A 40-year-old Caucasian male patient (ASA II, height $195 \mathrm{~cm}$, weight $101 \mathrm{~kg}$ ) underwent an annuloplasty of the mitral valve after sudden heart failure owing to ruptured chordae tendiniae resulting in severe mitral valve regurgitation. A pre-operative PAC was inserted uneventfully at the start of the surgical intervention, via the right internal jugular vein, with a normal pulmonary artery tracing obtained at $42 \mathrm{~cm}$. A mitral valve annuloplasty using a quadrangular resection and a Carpentier-Edwards prosthetic 30-mm ring was inserted. At the end of the operation, transoesophageal echocardiography confirmed a sufficient mitral valve. Post-operatively the patient recovered well on the intensive care unit (ICU), where he was extubated $4 \mathrm{~h}$ later.

The following day the patient was considered fit enough to be transferred to the ward and removal of the PAC was planned. Attempts to pull out and remove the PAC were not successful but it was felt that the catheter was loosening more and more. All of a sudden, without using too much force, the catheter came out, although it became immediately obvious that the catheter was sheared-off with a split end, leaving some $30 \mathrm{~cm}$ inside the jugular vein (Fig. 1). It was decided to use non-surgical retrievement first with a cardiac surgeon on stand-by. The cardiologist introduced a sheath via the left femoral vein under direct fluoroscopy, which showed migration of the fragment to the right ventricle. An Amplatz goose neck snare (ev3 Inc., Plymouth, MN) (1) was sited over the broken PAC and the rest of the snared catheter was retrieved easily. The patient recovered well without any further complication and was discharged from the hospital after 6 days.

Since its introduction several publications have reported complications associated with the use of PAC (2). A rare complication, however, can be a problematic catheter removal, which is not always successful and may even result in a disaster, when the removal procedure leads to tearing blood vessels with consequently massive blood loss and the need for resuscitation (3). Therefore no further pulling force should be exerted on the catheter as soon as a resistance is felt at the time of removal. Instead visualization and radiological diagnosis of the problem should be attempted first. A chest X-ray can give a first clue, while fluoroscopy can be a valuable diagnostic tool $(4,5)$. It can reveal an acute angle of the catheter suggesting fixation to the atrial wall. Furthermore, it is advised to use transoesophageal echocardiography to identify the exact location of catheter fixation $(6,7)$. Deformity of the atrial wall can be shown when traction on the PAC is applied. Fractured intravascular catheters tend to embolize if left in place and therefore the residual segment should be removed as soon as possible.

Surgeons and anaesthetists should be aware that PACs can be accidentally fixed whenever a suture is placed in the vicinity of catheters, and that one should be vigilant when removing catheters as they may become trapped along their intravascular track.

R. Schnabel

A. van Zundert

\section{References}

1. Saibil EA. Removal of a fractured retention wire of an Accufix 'J' pacemaker lead with an Amplatz goose neck snare. J Vasc Interv Radiol 1996; 3: 367-9.

2. Bossert T, Gummert JF, Bittner HB et al. Swan-Ganz-Catheterinduced severe complications in cardiac surgery: right ventricular perforation, knotting, and rupture of pulmonary artery. $J$ Card Surg 2006; 21: 292-5.

3. Huang HS, Wang HJ, Chen CH, Ho ST, Wong CS. Pulmonary artery rupture after attempted removal of a pulmonary artery catheter. Anesth Analg 2002; 95: 299-301.

4. Pfeiffer K, Widmann M, Deutsch H, Guggenberger H, Duda S, Seboltdt H. Unbemerkte Nahtfixation eines Swan-Ganz-Katheters in der Arteria pulmonalis während Herzoperation. Der Anaesthesist 1995; 44: 782-4.

5. Metha N, Lochab SS, Tempe DK, Trehan V, Nigam M. Successful nonsurgical removal of a knotted and entrapped pulmonary artery catheter. Cathet Cardiovasc Diagn 1998; 43: 87-9. 


\section{Letters to the Editor}

6. Wang HJ, Wang SS, Liau CS. Transesophageal echocardiographic diagnoses of intracardiac entrapment of a Swan-GanzCatheter in open heart surgery. J Am Soc Echocardiogr 2004; 17: 277-9.

7. Rupert E, Paul A, Mukherji J. Transoesophageal echocardiography: a useful tool to diagnose entrapment of pulmonary artery catheter. Anaesthesia 2006; 61: 702-4.

\section{Address:}

André van Zundert

Catharina Hospital - Brabant Medical School

Michelangelolaan 2

NL-5623 EJ

Eindhoven

The Netherlands 